\title{
Monitoring of micturition and bladder volumes can replace routine indwelling urinary catheters in children receiving intravenous opioids: a prospective cohort study
}

\author{
Anita C. de Jong ${ }^{1}$ (D) Jolanda M. Maaskant ${ }^{2} \cdot$ Luitzen A. Groen $^{3} \cdot$ Job B. M. van Woensel $^{1}$ \\ Received: 10 December 2019 / Revised: 19 May 2020 / Accepted: 22 May 2020 / Published online: 11 June 2020 \\ (C) The Author(s) 2020
}

\begin{abstract}
In this prospective observational study, the incidence, risk factors and the time to event of urinary retention in children receiving intravenous opioids were evaluated. Urinary retention was confirmed by ultrasound following the inability to void for $8 \mathrm{~h}$ or earlier in patients experiencing discomfort. In total, 207 opioid episodes were evaluated, of which 199 (96.1\%) concerned morphine, in 187 children admitted to the pediatric ward or pediatric intensive care unit. The median age was 7.6 years (IQR 0.9-13.8), and $123(59.4 \%)$ were male. The incidence of urinary retention was 31/207 (15.0\%) opioid episodes, in which 14/32 $(43.8 \%)$ patients received continuous sedation for mechanical ventilation and 17/175 (9.7\%) received no sedation. Multivariable logistic regression analysis showed a significant association with continuous sedation (OR 6.8, 95\% CI 2.7-17.4, $p$ 0.001) and highest daily fluid intake (OR 0.8 per $10 \%$ deviation of normal intake, 95\% CI $0.7-0.9, p 0.01$ ). Opioid dosage, age and gender were not significantly associated. Most events $(28 / 31,90.3 \%)$ occurred within $24 \mathrm{~h}$.

Conclusion: The incidence of urinary retention in children receiving intravenous opioids is low, indicating that placement of urinary catheters is not routinely necessary in these patients. However, micturition and bladder volumes must be monitored, especially in sedated children and during the first $24 \mathrm{~h}$ of opioid administration.

What is Known:

- Great variation exists in the routine placement of urinary catheters in children receiving IV opioids.

What is New:

- Confirmed by ultrasound, the incidence of urinary retention in children receiving intravenous opioids in this study was $15 \%$, indicating that placement of urinary catheters is not routinely necessary in these patients.

- Children receiving continuous sedation for invasive mechanical ventilation showed a sevenfold greater risk of developing urinary retention than non-sedated patients.
\end{abstract}

Keywords Urinary retention · Urinary catheter $\cdot$ Analgesics $\cdot$ Opioid [pharmacological action] $\cdot$ Morphine $\cdot$ Child

Communicated by Gregorio Paolo Milani

Electronic supplementary material The online version of this article (https://doi.org/10.1007/s00431-020-03703-7) contains supplementary material, which is available to authorized users.

Anita C. de Jong

a.c.dejong@amsterdamumc.nl

Jolanda M. Maaskant

j.m.maaskant@amsterdamumc.nl

Luitzen A. Groen

1.a.groen@amsterdamumc.nl

Job B. M. van Woensel

j.b.vanwoensel@amsterdamumc.nl
1 Pediatric Intensive Care Unit, Emma Children's Hospital, Amsterdam UMC, University of Amsterdam, PO Box 22660, 1100 DD Amsterdam, the Netherlands

2 Department of Clinical Epidemiology, Biostatistics and Bioinformatics, Amsterdam UMC, University of Amsterdam, Amsterdam, the Netherlands

3 Department of Pediatric Urology, Emma Children's Hospital, Amsterdam UMC, University of Amsterdam, Amsterdam, the Netherlands 


$\begin{array}{ll}\text { Abbreviations } \\ \text { CAUTI } & \text { Catheter-associated urinary tract infection } \\ \text { CI } & \text { Confidence interval } \\ \text { IQR } & \text { Interquartile range } \\ \text { IV } & \text { Intravenous } \\ \text { OR } & \text { Odds ratio } \\ \text { PCA } & \text { Patient-controlled analgesia } \\ \text { PICU } & \text { Pediatric intensive care unit }\end{array}$

\section{Introduction}

Opioids are widely used for the management of pain and for sedation in children. However, opioids can cause acute urinary retention [1]. Urinary retention may cause pain or discomfort, but this is often masked by the opioid [2]. Although pharmacological management of opioid-related urinary retention is described in some studies [3], it often requires bladder catheterization to prevent over-distension which may result in long-term bladder dysfunction [2]. Urinary retention may be prevented by placement of an indwelling urinary catheter. However, this is in itself associated with discomfort, impaired mobilization and catheter-associated urinary tract infections (CAUTI). The rate of CAUTI in children varies strongly and may be up to 32 per 1000 catheter days [4].

The reported incidence of urinary retention in children receiving intravenous (IV) opioids varies widely from 1 to $64 \%$ [5-12]. This wide range is most likely explained by differences in patient characteristics and criteria for defining urinary retention. Yet the incidence has only been studied in primarily small cohorts of postoperative patients above 3 months old in non-critical care settings. In addition, risk factors in children have been scarcely studied. Consequently, great variation exists in the routine placement of indwelling urinary catheters in children receiving IV opioids [11]. The results of two recent studies indicated that urinary catheters are not routinely necessary in children receiving patient-controlled analgesia (PCA) following appendicitis $[9,11]$. However, none of the previous studies included children of all ages and children receiving continuous sedation for the facilitation of invasive mechanical ventilation.

Strategies to reduce inappropriate use of indwelling urinary catheters including strict indications for placement and removal contribute to reducing the risk of catheter-related complications and their associated costs. Therefore, the aim of this study is to evaluate the incidence of urinary retention in children receiving IV opioids, in order to increase our insight into the necessity for placement of a urinary catheter during opioid treatment. Secondary objectives are to identify independent risk factors for urinary retention and to establish the time to event. We hypothesize that children receiving IV opioids do not routinely require an indwelling urinary catheter.

\section{Materials and methods}

\section{Study design and setting}

This prospective observational study was performed at a tertiary children's hospital from January 2018 to November 2018. The study was approved by the local institutional review board (FWA00025191).

Patients were selected based on the following inclusion criteria: age $0-18$ years old, treatment with IV opioids continuously and/or via PCA for a minimum of $4 \mathrm{~h}$. Both patients admitted to the pediatric wards and pediatric intensive care unit (PICU) could be included. Each patient could be included once per hospital admission. If the initial indication for a urinary catheter was no longer present, patients who still received IV opioids were also included following removal of the catheter. Patients were excluded following occurrence of intraoperative urinary retention, by known urological pathology; if conduction of bladder ultrasound was not possible; epidural, spinal or caudal anaesthesia in the preceding $24 \mathrm{~h}$; treatment with paralytic agents; neuro-muscular diseases; prematurity (< 37 weeks of gestation) or admission to the neonatal intensive care unit. In line with Dutch legislation, written informed consent was obtained from parents or legal guardians of patients under 16 years of age, and in patients of 12 years or older also from the patients themselves.

Acute urinary retention was defined as the inability to void for the duration of $8 \mathrm{~h}$, or earlier in cases experiencing abdominal discomfort, in combination with a larger than expected for age bladder volume estimated by ultrasound scan $(<1$ year: $[\mathrm{kg} \times 7 \mathrm{~mL}], \geq 1$ year: [(age in years +2$) \times 30 \mathrm{~mL}])$ or above $400 \mathrm{~mL}[13,14]$. Bladder volumes were estimated twice by an automated bladder ultrasound device (Verathon Bladderscan Prime® [15]), further referred to as 'Bladderscan $®$.' In addition, due to the reported unreliable Bladderscan $\AA$ measurement in children below $25 \mathrm{~kg}$ or under 7 years of age [16, 17], in patients under 10 years of age, a conventional bladder ultrasound scan (M-Turbo, Fujifilm SonoSite Inc.® [18]) was made. Bladder volumes (millilitres) measured with a conventional bladder ultrasound were calculated as depth $\times$ height $\times$ width $\times 0.68$ (centimetres) [19]. The greatest estimated volume measured with either conventional bladder ultrasound or Bladderscan ${ }^{\circledR}$ was used to evaluate the bladder volume.

Toilet-trained children with a bladder volume larger than expected were first encouraged to void spontaneously for $30 \mathrm{~min}$ before diagnosing urinary retention. Depending on their mobility, a toilet, urinal, bedpan or diaper was used in a private room, when necessary assisted by a nurse or parent/ legal guardian, according to the child's preference.

Data on urinary retention-related pain or discomfort were collected from nursing patient reports. In patients admitted to the PICU, discomfort was evaluated by the nurses using the standardised COMFORT behavioural scale. In children 
admitted to the general pediatric wards, discomfort was evaluated by the nurses using the numerical rating scale, visual analogue scale or FLACC behavioural scale, depending on the patients' level of communication and awareness.

Follow-up of patients was carried out until $12 \mathrm{~h}$ after the cessation of IV opioids, with a maximum of 7 days after initiating the IV opioids. In cases in which urinary retention occurred, an indwelling urinary catheter was placed for the remaining duration of IV opioid treatment. Additionally, the initial catheterized bladder volume was recorded.

The variables that were considered as potential risk factors for developing urinary retention in children receiving IV opioids are shown in Table 2. These variables were selected based on the available literature and biological plausibility.

\section{Statistical analysis}

Data was analysed using R version 3.6.1 [20]. Continuous data with a normal distribution was reported as mean and standard deviation (SD), otherwise as median and interquartile range (IQR).

The incidence of urinary retention was calculated for episodes of IV opioids of the overall cohort, and for subgroups with evaluated risk factors. Univariable and multivariable binomial logistic regression analyses were performed to study the association between potential risk factors and the occurrence of urinary retention. A $p$ value of $<0.05$ was considered statistically significant. Log-linearity of continuous variables was evaluated via visual inspection, categorization and testing of non-linear transformations. In cases of non-log-linearity, categorization of variables was conducted. Variables with a $p$ value $<0.1$ in the univariable analysis were included into a multivariable model. Multi-collinearity of variables was evaluated by a variance inflation factor below five. A maximum ratio of ten events per variable was applied in the model. If more variables were eligible, decision for inclusion was based on the $p$ value, the variance inflating factor and clinical relevance. Variable selection was performed via stepwise backward selection. Risk factors only present in subgroups were only univariable analysed.

Opioid dose included continuously administered IV opioids, IV boluses and PCA and was analysed per $10 \mathrm{mcg} / \mathrm{kg} /$ h. If opioids other than IV morphine were administered, the equivalent dose was calculated [21]. If patients switched between morphine and another type of IV opioid, the type of opioid was evaluated as morphine. Peak opioid dose was analysed over four consecutive hours. Mean opioid dose was analysed until the occurrence of urinary retention. In patients in whom there were no signs of urinary retention, the opioid dose was analysed until the median time to the event of the overall cohort. Highest daily fluid intake was obtained from the day during the study period with the highest fluid intake and was analysed per $10 \%$ deviation of common practice of normal intake for age and bodyweight [22].

The time to event was analysed by cumulative incidence from initiating the IV opioids or following removal of the initial urinary catheter, until the occurrence of urinary retention or until $12 \mathrm{~h}$ after the cessation of IV opioids, with a maximum follow-up of 7 days.

Handling of missing data is provided in the Online Resource.

\section{Results}

\section{Participants}

A total of 231 patients, receiving 252 IV opioid episodes, were eligible for participation. A total of 187 patients went on to be included, of whom 207 opioid episodes were evaluated. Of these 187 patients, $170(90.9 \%)$ were included once, 16 $(8.6 \%)$ were included twice and one $(0.5 \%)$ was included five times. Forty-five opioid episodes were excluded for reasons of failure to include the patient within $8 \mathrm{~h}$ after initiation of IV opioids $(n=27)$, declined informed consent $(n=9)$, social circumstances $(n=6)$ and language barrier $(n=3)$. The patient characteristics are summarized in Table 1.

The median observation time was $43.2 \mathrm{~h}$ (IQR 20.6-71.2). Follow-up was continued until cessation of IV opioids in 192/ 207 (92.8\%) episodes. In 7/207 (3.4\%) episodes, follow-up was terminated prematurely after a median of $38.5 \mathrm{~h}$ (IQR 18.0-60.5) due to hospital discharge or medical indication for placement of a urinary catheter. The observed period of these episodes was included in our analysis. Follow-up was discontinued in 8/207 (3.9\%) episodes in which patients received IV opioids for more than 7 days without occurrence of urinary retention.

\section{Incidence of urinary retention}

In total, spontaneous voiding occurred at least every $8 \mathrm{~h}$ in 153/207 (73.9\%) IV opioid episodes. In 52 episodes, a total of 59 ultrasound scans were performed, in which the bladder volume was larger than expected for age in 35 . In four episodes, patients voided spontaneously within $30 \mathrm{~min}$ following performance of the abdominal ultrasound. Therefore, the overall incidence of urinary retention in episodes of children receiving IV opioids was $31 / 207$ (15.0\%), in which $14 / 32$ $(43.8 \%)$ episodes the patient received continuous sedation for the facilitation of invasive mechanical ventilation and in 17/175 (9.7\%) episodes patients did not receive continuous sedation. Two patients, both of whom were included twice, developed urinary retention only during one opioid episode. Therefore, the overall number needed to treat was one case requiring placement of a urinary catheter per seven episodes 
Table 1 Patient characteristics

$n=207$ opioid episodes, related to 187 individual patients

Age (years), median (IQR)

Bodyweight ( $\mathrm{kg}$ ), median (IQR)

Male gender, $\%$

Ethnicity, \%

Caucasian

Black

North African/Arabic

Other/mixed/unable to obtain

Reason for admission, \%

Surgical

Respiratory

Circulatory/cardio-surgery

Neurology/neuro-surgery

Hematology

Oncology

Trauma

Other

Localization of surgery, $\%^{\mathrm{a}}$

Head

Facial/mouth

Ear, nose, throat

Thoracic

Abdominal

Orthopedic

Other

Anaesthesia, \% ${ }^{\mathrm{b}}$

Hospital length of stay (days), median (IQR)

PICU admission, \%

PRISM III score, median (IQR)

Continuous sedation, for invasive mechanical ventilation, $\%$

28-day mortality, \%

Type of IV opioid, \%

Morphine, or switch between morphine and other $\quad 96.1$

$\begin{array}{ll}\text { Buprenorphine only } & 2.9\end{array}$

Fentanyl only 1.0

Administration type of IV opioid, \%

Basal rate only 27.5

$\begin{array}{ll}\text { PCA only } & 21.7\end{array}$

$\begin{array}{lr}\text { Basal rate and PCA/boluses } & 50.8\end{array}$

IV opioid dose (morphine equivalent, $\mathrm{mcg} / \mathrm{kg} / \mathrm{h}$ ), median $(\mathrm{IQR})^{\mathrm{d}}{ }^{\mathrm{d}} \mathrm{e} \quad 14.0(9.0-21.4)$

Duration of IV opioids (h), median (IQR) ${ }^{\mathrm{d}}$

Co-medication associated with urinary retention, \%

Co-medication, overall $\quad 74.9$

$\begin{array}{lc}\text { Anticholinergic drugs } & 12.1\end{array}$

$\begin{array}{ll}\text { Benzodiazepines } & 6.8\end{array}$

Non-steroid anti-inflammatory drugs $\quad 53.6$

$\begin{array}{lc}\text { Alpha-adrenoreceptor agonists (continuously) } & 17.4\end{array}$

Other (theophylline, vincristine, baclofen, estrogens) 3.9

Removal of indwelling urinary catheter ${ }^{\mathrm{f}} \quad 11.1$

$I Q R$ interquartile range, $I V$ intravenous, $P C A$ patient-controlled analgesia, PICU pediatric intensive care unit, PRISM score pediatric risk of mortality score

${ }^{\text {a }}$ Seven days preceding or during the study period $(n=137)$

${ }^{\mathrm{b}}$ Twenty-four hours preceding or during the study period

${ }^{\mathrm{c}}$ In PICU patients $(n=65)$

${ }^{\mathrm{d}}$ Cases: until the occurrence of individual urinary retention, non-cases: until the median time to event of the overall cohort $(9.0 \mathrm{~h})$

${ }^{\mathrm{e}}$ Excluding intra-operative opioids

${ }^{\mathrm{f}}$ Patients were included following removal of the catheter 
of IV opioids. In patients receiving continuous sedation for the facilitation of invasive mechanical ventilation, the number needed to treat was one catheter per two opioid episodes and in patients who did not receive continuous sedation one catheter per 11 opioid episodes.

In patients who developed urinary retention, the median estimated bladder volume was $138 \%$ (IQR 111-162) of expected maximum bladder capacity for age. Of these cases, 14/ $31(45.2 \%)$ experienced abdominal pain or noticeable discomfort.

\section{Risk factors}

The univariable analyses of potential risk factors are presented in Table 2, and the multivariable model is presented in Table 3. The variables 'reason for admission' and 'PICU admission,' that were both statistically significant in univariable analysis, were not included in the multivariable model for the following reasons. Patients with the admission criterion 'respiratory' were all PICU patients requiring invasive mechanical ventilation. Therefore, in the multivariable model, we only included 'receiving continuous sedation for the facilitation of invasive mechanical ventilation.' Since 32/65 (49.2\%) of all participating PICU patients were mechanically ventilated and the criteria for PICU admission vary amongst centres, we excluded PICU admission in the multivariable model. For reasons of clinical relevance, we included mean opioid dose in the multivariable model despite its non-significance in the univariable analysis.

Following stepwise backward logistic regression analysis, only continuous sedation for the facilitation of mechanical ventilation (adjusted OR $=6.8,95 \%$ CI 2.7-17.4, $p<0.001$ ) and highest daily fluid intake (adjusted OR $=0.8$ per $10 \%$ deviation of the normal intake, 95\% CI $0.7-0.9, p=0.01$ ) remained as statistically significant factors associated with the subsequent acquirement of urinary retention. The variance inflating factors were below 1.1, indicating no multicollinearity amongst variables.

\section{Time to event}

The overall median time to event was $9.0 \mathrm{~h}$ (IQR 7.1-13.3), with $9.0 \mathrm{~h}$ (IQR 7.5-20.5) in episodes of patients receiving continuous sedation for the facilitation of invasive mechanical ventilation and $8.5 \mathrm{~h}$ (IQR 6.7-12.8) in episodes of patients who did not receive continuous sedation (Fig. 1). In 28/31 $(90.3 \%)$ cases, the urinary retention occurred within $24 \mathrm{~h}$ following IV opioid administration or removal of the urinary catheter. Two patients receiving continuous sedation for the facilitation of invasive mechanical ventilation developed urinary retention 3 days after the initiation of IV opioids, both in the absence of any opioid dose adjustments but initiation of benzodiazepines in one case. Two teenage cases refused placement of a urinary catheter and eventually voided spontaneously overnight.

\section{Missing data}

We could not perform a reliability test, because in patients who developed urinary retention, the time between performing the bladder ultrasound scan and the initial bladder volumes measured following catheterization varied.

The missing data are presented in the Online Resource.

\section{Discussion}

In children receiving IV opioids, we found that acute urinary retention, as confirmed by bladder ultrasound scan, occurred in $15.0 \%$ of episodes. Previous studies describe an incidence ranging from 1 to $64 \%$ [5-12]. However, ultrasound confirmation of bladder volumes was performed in only two of these previous studies $[8,11]$. Alfheim et al. reported an incidence of $64 \%$ following cleft palate surgery, which they hypothesized to be related to high dosages of post-operative morphine, but this was not analysed [8]. In their study, despite the fact that this technique is known to be inaccurate in children below $25 \mathrm{~kg}$ or under 7 years old [16, 17], Bladderscan® was used even though all children were aged less than 20 months. Sobrino et al. found an incidence of $4 \%$, confirmed by ultrasound scan after clinical symptoms in children receiving PCA following appendicitis [11]. Since over half of our cases experienced no evident abdominal pain or discomfort, the single criterion of clinical symptoms used in the latter study may explain the higher incidence of urinary retention in our study population.

Since none of the previous studies included children receiving continuous sedation for the facilitation of invasive mechanical ventilation, we cannot compare the incidence of $43.8 \%$ we found in this subgroup. Our results suggest that these children have a sevenfold greater risk of developing urinary retention than non-sedated patients. The large number of critically ill patients included in this study could in part explain these results. It is known that critically ill children may have reduced physiological clearance of opioids due to impaired hepatic and/or renal function [23, 24]. In addition, encouragement of spontaneous voiding may not always be possible in sedated patients. In contrast to the study of Verhamme et al. [1], we did not observe a significant risk of reported co-medication, although invasively mechanically ventilated patients often receive poly-pharmacology.

Unexpectedly, we found a negative association of highest daily fluid intake and urinary retention. Although speculative, a high daily fluid intake might be positively associated with renal opioid clearance or dilution of active opioid metabolites. Alternatively, a low frequency of voiding in children with low 
Table 2 Univariable analyses of risk factors associated with acute urinary retention in children receiving IV opioids

\begin{tabular}{|c|c|c|c|c|}
\hline Variables & Beta & OR & $95 \% \mathrm{CI}$ & $p$ value \\
\hline Age, years & -0.0 & 0.8 & $0.9-1.0$ & 0.47 \\
\hline Bodyweight, kg & -0.0 & 1.0 & $1.0-1.01$ & 0.40 \\
\hline Gender - male & 0.1 & 1.1 & $0.5-2.5$ & 0.82 \\
\hline \multicolumn{5}{|l|}{ Ethnicity } \\
\hline Caucasian & 1.0 & - & - & - \\
\hline North African/Arabic & -0.6 & 0.9 & $0.0-5.6$ & 0.89 \\
\hline Black & -0.2 & 0.9 & $0.2-2.5$ & 0.74 \\
\hline Mixed/other/unable to obtain & -1.1 & 0.3 & $0.0-1.8$ & 0.28 \\
\hline \multicolumn{5}{|l|}{ Reason for admission } \\
\hline Surgery & 1.0 & - & - & - \\
\hline Respiratory & 1.2 & 3.5 & $1.1-10.0$ & $0.02 *$ \\
\hline Circulatory/cardio-surgery & 0.7 & 2.0 & $0.3-9.1$ & 0.42 \\
\hline Neurology/neurosurgery & 1.3 & 3.6 & $1.0-11.9$ & $0.04 *$ \\
\hline Haematology & -0.2 & 0.8 & $0.2-3.2$ & 0.77 \\
\hline Oncology & -15.5 & 0.0 & NA & 0.99 \\
\hline Trauma & 1.6 & 3.2 & $0.4-16.6$ & 0.56 \\
\hline Other & 0.7 & 2.0 & $0.1-14.8$ & 0.55 \\
\hline Hospital length of stay, days & -0.0 & 1.0 & $1.0-1.0$ & 0.62 \\
\hline PICU admission & 1.5 & 4.5 & $2.0-10.2$ & $<0.001 *$ \\
\hline PRISM III score ${ }^{\mathrm{a}}$ & -0.0 & 0.9 & $0.8-1.1$ & 0.53 \\
\hline Continuous sedation, for mechanical ventilation & 2.0 & 7.2 & $3.1-17.2$ & $<0.001 *$ \\
\hline \multicolumn{5}{|l|}{ Opioid type IV } \\
\hline Morphine, or switch between morphine and other & 1.0 & - & - & - \\
\hline Buprenorphine only & -15.8 & 0.0 & NA & 0.99 \\
\hline Fentanyl only & -15.8 & 0.0 & NA & 1.00 \\
\hline \multicolumn{5}{|l|}{ Administration type of IV opioids } \\
\hline Basal rate only & 1.0 & - & - & - \\
\hline PCA only & -0.1 & 0.9 & $0.3-2.9$ & 0.92 \\
\hline Basal rate and PCA/bolus & 0.2 & 1.2 & $0.5-3.1$ & 0.72 \\
\hline \multicolumn{5}{|l|}{ Opioid dose } \\
\hline Mean morphine equivalent dose, $10 \mathrm{mcg} / \mathrm{kg} / \mathrm{h}^{\mathrm{b}}$ & 0.2 & 1.2 & $1.0-1.4$ & 0.11 \\
\hline Mean morphine equivalent dose, $10 \mathrm{mcg} / \mathrm{kg} / \mathrm{h}^{\mathrm{c}}$ & 0.0 & 1.0 & $0.9-1.1$ & 0.78 \\
\hline Peak morphine equivalent dose, $10 \mathrm{mcg} / \mathrm{kg} / \mathrm{h}^{\mathrm{b}, \mathrm{d}, \mathrm{e}}$ & 0.1 & 1.1 & $1.0-1.1$ & 0.33 \\
\hline Peak morphine equivalent dose, $10 \mathrm{mcg} / \mathrm{kg} / \mathrm{h}^{\mathrm{c}, \mathrm{d}, \mathrm{e}}$ & 0.0 & 1.0 & $1.0-1.1$ & 0.67 \\
\hline Anaesthesia $^{\mathrm{f}}$ & -0.2 & 0.8 & $0.4-1.8$ & 0.62 \\
\hline Intra-operative morphine equivalent dose, $100 \mathrm{mcg} / \mathrm{kg} / \mathrm{h}$ & 0.3 & 1.3 & $1.0-1.6$ & $0.03 *$ \\
\hline Duration of anaesthesia, $\mathrm{h}$ & -0.2 & 0.8 & $0.5-1.7$ & 0.35 \\
\hline Intra-operative fluid replacement, $10 \mathrm{ml} / \mathrm{kg}$ & 0.3 & 1.4 & $1.0-1.9$ & $0.04 *$ \\
\hline \multicolumn{5}{|l|}{ Localization of surgery ${ }^{\mathrm{g}}$} \\
\hline No surgery & 1.0 & - & - & - \\
\hline Head & 0.6 & 1.8 & $0.4-7.4$ & 0.43 \\
\hline Mouth, facial or ear, nose, throat & 17.0 & 0.0 & NA & 0.99 \\
\hline Thoracic & 0.3 & 1.4 & $0.4-4.0$ & 0.57 \\
\hline Abdominal & -0.5 & 0.6 & $0.2-1.8$ & 0.37 \\
\hline Orthopaedic & -0.1 & 0.9 & $0.3-2.8$ & 0.84 \\
\hline Other & -0.0 & 1.0 & $0.1-6.8$ & 0.98 \\
\hline
\end{tabular}


Table 2 (continued)

\begin{tabular}{|c|c|c|c|c|}
\hline Variables & Beta & OR & $95 \% \mathrm{CI}$ & $p$ value \\
\hline Neurological illness & 0.3 & 1.4 & $0.5-3.5$ & 0.52 \\
\hline \multicolumn{5}{|l|}{ Fluid intake } \\
\hline Highest daily fluid intake $^{\mathrm{h}}$ & -0.3 & 0.8 & $0.7-0.9$ & $0.002 *$ \\
\hline \multicolumn{5}{|l|}{ Mean daily fluid intake ${ }^{\mathrm{i}}$} \\
\hline $80-120 \%$ & 1.0 & - & - & - \\
\hline$<80 \%$ & 0.7 & 2.0 & $0.7-5.2$ & 0.16 \\
\hline$>120 \%$ & -1.2 & 0.3 & $0.1-1.1$ & 0.11 \\
\hline Removal of indwelling urinary catheter ${ }^{j}$ & 0.2 & 1.2 & $0.3-3.6$ & 0.73 \\
\hline Toilet trained & -0.2 & 0.8 & $0.4-1.1$ & 0.55 \\
\hline \multicolumn{5}{|l|}{ Voiding-related mobility ${ }^{\mathrm{k}}$} \\
\hline Bedrest & 1.0 & - & - & - \\
\hline Bedside & 0.1 & 1.1 & $0.3-3.5$ & 0.89 \\
\hline Mobile for toilet & -1.5 & 0.2 & $0.0-1.3$ & 0.17 \\
\hline \multicolumn{5}{|l|}{ Co-medication associated with urinary retention } \\
\hline Co-medication, overall & 0.9 & 2.4 & $0.9-8.5$ & 0.10 \\
\hline Anticholinergic drugs & 0.4 & 1.5 & $0.5-4.1$ & 0.41 \\
\hline Benzodiazepines & -0.9 & 0.4 & $0.0-2.2$ & 0.43 \\
\hline Non-steroid anti-inflammatory drugs & -0.3 & 0.8 & $0.4-1.7$ & 0.53 \\
\hline Alpha-adrenoreceptor agonists (continuously) & 0.2 & 1.2 & $0.4-2.9$ & 0.76 \\
\hline Other (theophylline, vincristine, baclofen, estrogens) & -0.2 & 0.8 & $0.0-4.8$ & 0.84 \\
\hline
\end{tabular}

$C I$ confidence interval, $I Q R$ interquartile range, $I V$ intravenous, $O R$ odds ratio, $P I C U$ pediatric intensive care unit, $P C A$ patient-controlled analgesia, PRISM score pediatric risk of mortality score

$* p$ value $<0.05$

${ }^{\mathrm{a}}$ Of PICU patients $(n=65)$

${ }^{\mathrm{b}}$ Excluding intra-operative opioids

${ }^{\mathrm{c}}$ Including intra-operative opioids

${ }^{\mathrm{d}}$ Peak of 4-h mean dose

${ }^{\text {e }}$ Cases: until the occurrence of urinary retention; non-cases: until the median time to event of the overall cohort $(9.0 \mathrm{~h})$

${ }^{\mathrm{f}}$ Twenty-four hours preceding or during the study period

${ }^{\mathrm{g}}$ Seven days preceding or during the study period

${ }^{\mathrm{h}}$ Per $10 \%$ deviation of normal intake for age and bodyweight, obtained per patient from the day during the study period with the highest fluid intake

${ }^{\mathrm{i}}$ Percentage of deviation of normal intake for age and bodyweight, obtained from the mean daily fluid intake

${ }^{\mathrm{j}}$ Patients were included following removal of the catheter

${ }^{\mathrm{k}}$ If toilet trained $(n=117)$

Table 3 Multivariable analysis of risk factors associated with acute urinary retention in children receiving IV opioids

\begin{tabular}{|c|c|c|c|c|}
\hline Variables & Beta & Adjusted OR & $95 \% \mathrm{CI}$ & $p$ value \\
\hline Continuous sedation, for mechanical ventilation & 1.9 & 6.8 & $2.7-17.4$ & $<0.001 *$ \\
\hline Highest daily fluid intake $^{\mathrm{a}}$ & -0.2 & 0.8 & $0.7-0.9$ & $0.01 *$ \\
\hline Mean morphine equivalent dose, $10 \mathrm{mcg} / \mathrm{kg} / \mathrm{h}^{\mathrm{b}}$ & 0.2 & 1.3 & $1.0-1.6$ & 0.07 \\
\hline
\end{tabular}

$C I$ confidence interval, $I V$ intravenous, $O R$ odds ratio

$* p$ value $<0.05$

${ }^{\text {a }}$ Per $10 \%$ deviation of normal intake for age and bodyweight, obtained per patient from the day during the study period with the highest fluid intake

${ }^{\mathrm{b}}$ Excluding intra-operative opioids 


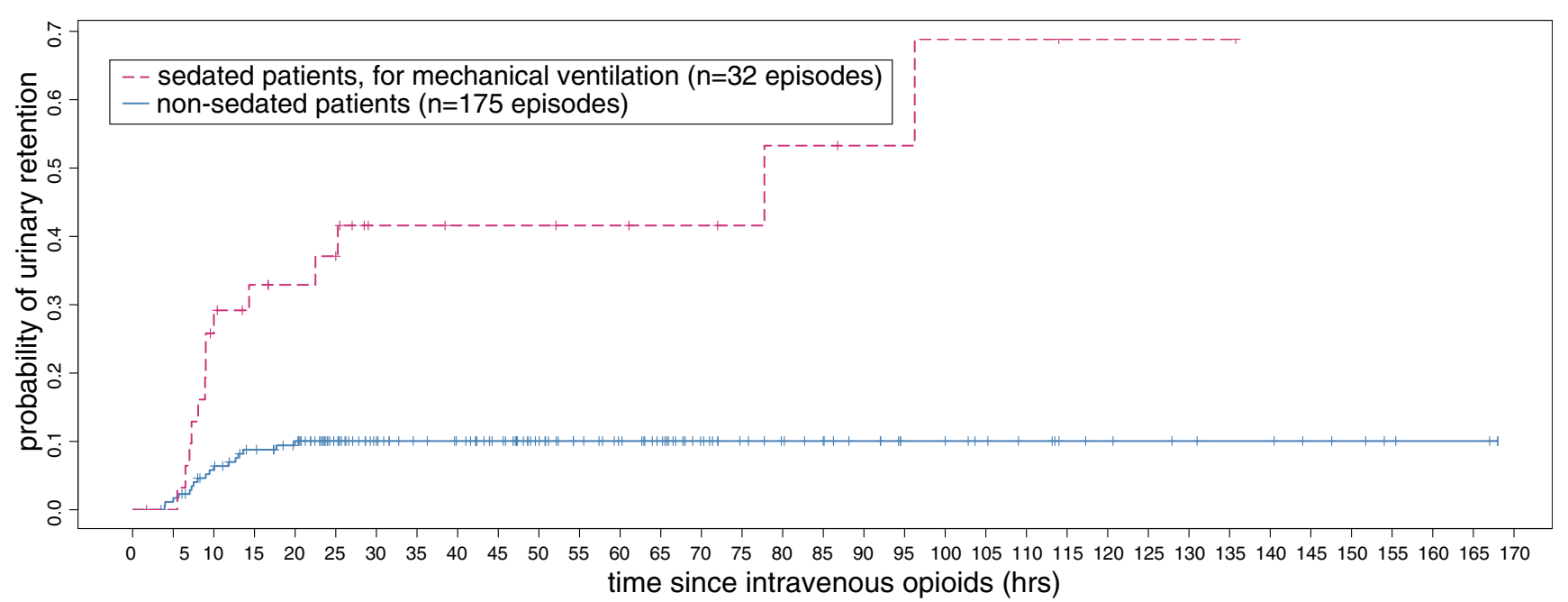

Fig. 1 Cumulative incidence of urinary retention in children receiving IV opioids

daily fluid intake might have resulted in observing a full bladder, especially in children in whom encouragement of spontaneous voiding was not possible.

In contrast to the general assumption that a dose-response relationship exists between opioids and occurrence of urinary retention, in line with previous pediatric and adult studies, we failed to demonstrate this relationship [9, 12, 25]. Potentially, there could be a certain threshold above which the dose of opioid may not give any further increased risk of urinary retention. In line with the reported studies in children over 5 years old $[9,12]$, we neither could demonstrate age as an independent risk factor. As morphine clearance is positively correlated with gestational age [26], one could speculate that neonates may be at greater risk of developing urinary retention. Since we only included 11 neonates, we were unable to confirm this hypothesis. Controversy exists regarding the impact of gender on the development of urinary retention. In line with some other studies $[9,12]$, we too were unable to demonstrate an association with gender. In contrast, Gatti et al. reported a threefold increase in drug-related urinary retention in boys compared to girls [27].

To our knowledge, the time to development of urinary retention following the commencement of IV opioids has not been previously studied, whereas we believe that this information may be of great clinical relevance for the monitoring of spontaneous micturition. We identified a median time to event of $9 \mathrm{~h}$ after initiating the IV opioids or removal of the initial urinary catheter and in $90 \%$ of the cases this occurred within the first $24 \mathrm{~h}$. If adverse effects are more likely to be related to morphine itself rather than the slowly accumulating effect of its more potent active metabolite morphine-6glucuronide [28], this might support our observation that urinary retention mainly occurs during the first $24 \mathrm{~h}$ of opioid administration.
The major strengths of our study are the size of the study population and the clear definition of urinary retention including confirmatory ultrasound scan. Nevertheless, the following limitations should be considered when interpreting our results. Firstly, due to the lack of a uniform definition, and as urinary retention often remains asymptomatic $[2,29]$, the observed incidence in our study might be an overestimate when compared to studies using the definition 'the requirement for catheterization' $[5,9,10$, 12]. Secondly, since the incidence in previous studies varies widely, we were unable to make a reliable power calculation. Given the low observed incidence of urinary retention in our study, we were limited to a multivariable analysis of three variables. Thirdly, identified risk factors may have been confounded by pre-opioid bladder volume [25], which was not analysed for reasons of feasibility. Finally, the identified time to event might have been influenced by our definition of urinary retention following an absence of spontaneous voiding over an 8-h interval. One unresolved question which remains is whether urinary retention in children occurs as a single or repeated event.

In conclusion, a low incidence of urinary retention in children receiving IV opioids was observed, indicating that indwelling urinary catheters are not routinely necessary in these patients. However, micturition and bladder volumes must be well monitored, especially in mechanically ventilated children receiving continuous sedation, who appeared to have an increased risk of developing urinary retention. This monitoring is of the greatest importance during the first $24 \mathrm{~h}$ following IV opioid administration or removal of the urinary catheter. Development of a uniform definition of urinary retention in children is necessary in order to conduct further research into risk factors. 
Acknowledgements We thank A. Bogaert-Vedder for patient recruitment, E.R. Oltmans for data collection and C.S. Ward for language editing. Furthermore, we thank R.R. van Rijn, J.P.M. Derikx, P.F.M. Kuks, M. de Neef, M.H. Otten and A.H.M. Bouts for sharing their expertise.

Authors' contributions Anita C. de Jong: conceptualization, patient recruitment, investigation, data collection and curation, statistical analyses, writing - original draft preparation, review and editing. Jolanda M. Maaskant: conceptualization - revision, supervision of statistical analyses, writing - review and editing. Luitzen A. Groen: conceptualization - revision, patient recruitment, writing - review and editing. Job B.M. van Woensel: conceptualization - revision, writing - review and editing, ultimately responsible for this study. All authors read and approved the final manuscript.

\section{Compliance with ethical standards}

Ethical approval The study has been approved by the local institutional review board (FWA00025191) and has been performed in accordance with the ethical standards as laid down in the 1964 Declaration of Helsinki as revised in 2013.

Informed consent Written informed consent was obtained from all individual patients included in the study, from parents of or legal guardian of patients under 16 years of age and by patients themselves when 12 years or older.

Conflict of interest The authors declare that they have no conflict of interest.

Open Access This article is licensed under a Creative Commons Attribution 4.0 International License, which permits use, sharing, adaptation, distribution and reproduction in any medium or format, as long as you give appropriate credit to the original author(s) and the source, provide a link to the Creative Commons licence, and indicate if changes were made. The images or other third party material in this article are included in the article's Creative Commons licence, unless indicated otherwise in a credit line to the material. If material is not included in the article's Creative Commons licence and your intended use is not permitted by statutory regulation or exceeds the permitted use, you will need to obtain permission directly from the copyright holder. To view a copy of this licence, visit http://creativecommons.org/licenses/by/4.0/.

\section{References}

1. Verhamme KM, Sturkenboom MC, Stricker BH, Bosch R (2008) Drug-induced urinary retention: incidence, management and prevention. Drug Saf 31(5):373-388

2. Madersbacher H, Cardozo L, Chapple C, Abrams P, Toozs-Hobson P, Young JS, Wyndaele JJ, De Wachter S, Campeau L, Gajewski JB (2012) What are the causes and consequences of bladder overdistension? ICI-RS 2011. Neurourol Urodyn 31(3):317-321. https://doi.org/10.1002/nau.22224

3. Reiter PD, Clevenger AC (2019) Nalbuphine reduces opioidassociated urinary retention in pediatric patients. Pediatr Crit Care Med 20(5):e240-e244. https://doi.org/10.1097/pcc. 0000000000001920

4. Araujo da Silva AR, Marques AF, Biscaia di Biase C, Zingg W, Dramowski A, Sharland M (2018) Interventions to prevent urinary catheter-associated infections in children and neonates: a systematic review. J Pediatr Urol 14(6):556.e551-556.e559. https://doi.org/10. 1016/j.jpurol.2018.07.011

5. Esmail Z, Montgomery C, Courtrn C, Hamilton D, Kestle J (1999) Efficacy and complications of morphine infusions in postoperative paediatric patients. Paediatr Anaesth 9(4):321-327

6. Cropper J, Hutchison L, Llewellyn N (2003) Post-operative retention of urine in children. Paediatr Nurs 15(7):15-18. https://doi.org/ 10.7748/paed2003.09.15.7.15.c869

7. Warren DT, Bowen-Roberts T, Ou C, Purdy R, Steinbok P (2010) Safety and efficacy of continuous morphine infusions following pediatric cranial surgery in a surgical ward setting. Childs Nerv Syst 26(11):1535-1541. https://doi.org/10.1007/s00381-010$1123-0$

8. Alfheim HB, Steenfeldt-Foss A, Hanem S, Rosseland LA (2016) High risk of postoperative urinary retention in 1-year-old cleft palate patients: an observational study. J Perianesth Nurs 31(1):41-48. https://doi.org/10.1016/j.jopan.2014.05.016

9. Yu YR, Sola R Jr, Mohammed S, Lackey JT, John S, Rosenfeld E, Zhang W, St Peter SD, Shah SR (2018) Foley catheters are not routinely necessary in children treated with patient-controlled analgesia following perforated appendicitis. J Pediatr Surg. 53:20322035. https://doi.org/10.1016/j.jpedsurg.2018.03.024

10. Thomas P, Knott EM, Sharp NE, St Peter SD (2013) Implications of Foley catheterization in children with perforated appendicitis. J Surg Res 184(1):337-340. https://doi.org/10.1016/j.jss.2013.05. 026

11. Sobrino JA, Axt J, Sujka JA, Benedict LA, Wedel L, Millspaugh D, St Peter SD (2019) Withholding urinary catheters in children receiving patient-controlled analgesia for appendicitis. J Surg Res 233:100-103. https://doi.org/10.1016/j.jss.2018.07.060

12. Friske TC, Sola R, Yu YR, Jamal AR, Rosenfeld E, Zhu H, Mazziotti MV, St Peter SD, Shah SR (2018) Are Foley catheters needed after minimally invasive repair of pectus excavatum? Surgery 163(4):854-856. https://doi.org/10.1016/j.surg.2017.10. 049

13. Fairhurst JJ, Rubin CM, Hyde I, Freeman NV, Williams JD (1991) Bladder capacity in infants. J Pediatr Surg 26(1):55-57

14. Koff SA (1983) Estimating bladder capacity in children. Urology 21(3):248

15. Bladderscan Prime operations and maintenance manual (2016). Verathon Inc, Botherl, U.S.A.

16. De Gennaro M, Capitanucci ML, Di Ciommo V, Adorisio O, Mosiello G, Orazi C, Tubaro A (2006) Reliability of bladder volume measurement with BladderScan in paediatric patients. Scand J Urol Nephrol 40(5):370-375. https://doi.org/10.1080/ 00365590600679137

17. Koomen E, Bouman E, Callewaerdt P, Vos GD, Prins MH, Anderson BJ, Marcus MA (2008) Evaluation of a non-invasive bladder volume measurement in children. Scand J Urol Nephrol 42(5):444-448. https://doi.org/10.1080/00365590802054600

18. M-Turbo Ultrasound System User Guide (2014) Fujifilm. SonoSite Inc, Bothell

19. Byun SS, Kim HH, Lee E, Paick JS, Kamg W, Oh SJ (2003) Accuracy of bladder volume determinations by ultrasonography: are they accurate over entire bladder volume range? Urology 62(4):656-660

20. R Core Team. R: a language and environment for statistical computing. (2018) R Foundation for Statistical Computing http://www. R-project.org/.

21. Brennan MJ, Fudin J., R.J. P Opioid conversion calculator. Vertical Health LLC. https://opioidcalculator.practicalpainmanagement. com/conversion.php. Accessed 15-9-2018 2018

22. Waterbehoefte kinderen. (1993) Gezondheidsnet. https://www. gezondheidsnet.n1/ziekten/waterbehoefte-kinderen. Accessed 1010-2019 
23. Altamimi MI, Choonara I, Sammons H (2015) Inter-individual variation in morphine clearance in children. Eur J Clin Pharmacol 71(6):649-655. https://doi.org/10.1007/s00228-015-1843-x

24. Berkenstadt H, Segal E, Mayan H, Almog S, Rotenberg M, Perel A, Ezra D (1999) The pharmacokinetics of morphine and lidocaine in critically ill patients. Intensive Care Med 25(1):110-112

25. Keita H, Diouf E, Tubach F, Brouwer T, Dahmani S, Mantz J, Desmonts JM (2005) Predictive factors of early postoperative urinary retention in the postanesthesia care unit. Anesth Analg 101(2): 592-596, table of contents. https://doi.org/10.1213/01.ane. 0000159165.90094.40

26. Pacifici GM (2016) Metabolism and pharmacokinetics of morphine in neonates: a review. Clinics (Sao Paulo) 71(8):474-480. https:// doi.org/10.6061/clinics/2016(08)11
27. Gatti JM, Perez-Brayfield M, Kirsch AJ, Smith EA, Massad HC, Broecker BH (2001) Acute urinary retention in children. J Urol 165(3):918-921

28. Hain RD, Hardcastle A, Pinkerton CR, Aherne GW (1999) Morphine and morphine-6-glucuronide in the plasma and cerebrospinal fluid of children. Br J Clin Pharmacol 48(1):37-42

29. Lamonerie L, Marret E, Deleuze A, Lembert N, Dupont M, Bonnet F (2004) Prevalence of postoperative bladder distension and urinary retention detected by ultrasound measurement. Br J Anaesth 92(4): 544-546. https://doi.org/10.1093/bja/aeh099

Publisher's note Springer Nature remains neutral with regard to jurisdictional claims in published maps and institutional affiliations. 